\title{
China's Economy under COVID-19: Short-Term Shocks and Long-Term Changes
}

\author{
Zhiyi Liu1, Biliang Hu² \\ ${ }^{1}$ School of Economics and Resource Management (SERM), Emerging Markets Institute (EMI), Beijing Normal University, \\ Beijing, China \\ ${ }^{2}$ Emerging Markets Institute (EMI), Belt and Road School (BRS), Beijing Normal University, Beijing, China \\ Email:201431410006@mail.bnu.edu.cn, hubiliang@bnu.edu.cn
}

How to cite this paper: Liu, Z. Y., \& Hu, B. L. (2020). China's Economy under COVID-19: Short-Term Shocks and Long-Term Changes. Modern Economy, 11, 908-919. https://doi.org/10.4236/me.2020.114068

Received: February 24, 2020

Accepted: April 19, 2020

Published: April 22, 2020

Copyright (c) 2020 by author(s) and Scientific Research Publishing Inc. This work is licensed under the Creative Commons Attribution International License (CC BY 4.0).

http://creativecommons.org/licenses/by/4.0/ (c) (i) Open Access

\begin{abstract}
Under the impact of the epidemic and policy responses, China's economy in 2020 is expected to maintain a "low rebound and overall soundness". However, as a major public health event, the long-term impact of COVID-19 on China's economy should not be ignored. On the basis of confirming preventive savings at the micro level, this paper uses the macro neoclassical economic growth model to point out that COVID-19 epidemic may promote China's savings rate to increase the potential output level in the medium and long term. However, given the continued downturn in the global economy, a rebound in China's savings rate may exacerbate the global economic imbalance. Therefore, the Chinese government needs to make a good plan to strengthen international cooperation while actively encouraging consumption to stimulate domestic demand.
\end{abstract}

\section{Keywords}

COVID-19, China's Economy, Saving Tendency, Potential Output, Global Imbalance

\section{Introduction}

The outbreak of Corona Virus Disease 2019 (COVID-19) in late 2019 and early 2020 is very serious. Because COVID-19 is highly contagious and is spreading globally, its impact on China's economy and even global economy has become the focus of attention.

In the short term, under the impact of the COVID-19 epidemic, China's economy has suffered a "shutdown" due to large-scale isolation. Faced with public health emergencies, the Chinese government moved quickly. In addition to 
arranging special funds to ensure the prevention and control of the epidemic, in order to stabilize the economy, employment and financial market expectations, the Chinese government has also comprehensively used various policies such as fiscal, monetary, industrial, and employment policies. For the short-term trend of China's economy, a basic judgment is: Under the impact of the epidemic and the stimulation of macroeconomic policies, China's economy in 2020 is expected to maintain a "bottom rebound and overall soundness".

However, as a major public health event, COVID-19 has had a wild coverage in China and the world, which is rare in history and had severe impact on economic activities. In particular, the mid-to-long term impact on China's economy which is just undergoing transformation, upgrading, and quality degradation cannot be ignored. However, the current economic discussions about COVID-19 are mainly concentrated in the short term, and the discussions on the medium and long-term economy are still relatively small. Applying preventive savings motivation at the micro level and neo-classical economic growth models at the macro level, this paper points out that COVID-19 epidemic may promote China's savings rate, thereby increasing medium and long-term potential output. However, in view of the continued downturn in the global economy, the further increase of China's savings rate may exacerbate the risk of imbalances of the global economy. Therefore, the Chinese government is expected to actively encourage domestic consumption while strengthening international cooperation to promote the long-term stability of the global economy.

\section{Short-Term Epidemic Shock and Policy Response}

Regarding the short-term trends of China's economy, there are already many analyses of economic, academic and government-related organizations (Song, 2020; An \& Jia, 2020; Zhou, 2020; Lu et al., 2020). In the short term, the macroeconomic operation of the current country's economy is in a typical "emergency shock-policy response" framework.

Due to severe isolation measures, the epidemic not only caused a huge impact on China's domestic demand, but with the spread of COVID-19 worldwide, external demand has fallen significantly. Taken together, its impact can be roughly divided into three stages:

The first stage: During the Spring Festival, home isolation across the country resulted in weak consumption. Due to the reduction of residents' outing and public contact, all kinds of social activities were cancelled, scenic spots and shopping malls were closed, and a large number of enterprises in the wholesale and retail, catering, and tourism industries were suspended. For example, according to the "Report on the Investigation and Analysis of the Operation Status and Development Trend of China's Catering Industry during the COVID-19" released by the Chinese Cooking Association on February 12, "During the epidemic, $93 \%$ of catering companies chose to close their stores and $78 \%$ of catering companies lost more than $100 \%$ of their operating income".

The second stage: After the Spring Festival, workers are prevented from re- 
turning to work and logistics is not smooth, resulting in weak production. The epidemic caused partial paralysis and widespread stagnation of transportation and logistics, which had a greater impact on production and construction of enterprises. Moreover, of China's 290 million migrant workers, about 170 million are migrant workers leaving their hometown. According to the Ministry of Human Resources and Social Security, as of March 6, at least 50 million migrant workers have not returned to work. Many people belong to the group of "no income without work", and the slow return to work will have a great impact on the income and livelihood of these people ( $\mathrm{Hu}, 2020)$.

The third stage: As the epidemic spreads globally, overseas demand continues to shrink. Only when the epidemic was endemic in the country, the World Health Organization (WHO) announced that COVID-19 was included in the Public Health Emergency of International Concern (PHEIC) ${ }^{1}$, and many countries have restricted China's logistics flow. However, the greater impact occurred after the epidemic spread widely to Japan, South Korea, Italy, and even Europe and the United States. The spread of overseas epidemics and the magnitude of their impact on China's economy are still difficult to accurately assess (Shen, 2020). With the turbulence of the global financial market, the need to prevent the global financial crisis and even the economic crisis has sharply increased.

As of January-February 2020, China's macroeconomic data has shown negative growth since statistics were available. Among them, industrial value-added decreased by $13.5 \%$ year-on-year, service industry production index decreased by $13.0 \%$, total retail sales of social consumer goods decreased by $20.5 \%$, fixed asset investment decreased by $24.5 \%$, and exports denominated in RMB fell by $15.9 \%$. In order to prevent and control COVID-19, China has paid a heavy economic price.

With reference to the history of the Great Hanshin Earthquake in Japan in 1995, the SARS in China in 2003, the Wenchuan Earthquake in China in 2008, the H1N1 Flu Epidemic in the United States in 2009, the 311 Earthquake in Japan in 2011, and the MERS Epidemic in South Korea in 2015, it can be found that after the emergence of a public emergency, it often means huge economic losses. It often needs to use the power of the whole country and even use international aid to overcome difficulties (Joo et al., 2019).

Governments of various countries (or regions) have continuously summed up experiences in previous public emergencies, and gradually formed a relatively complete set of countermeasures. The main characteristics of these policies are: the focus is mainly on fiscal and monetary policy, which is basically centered on the central government, and integrates local governments, financial institutions, non-governmental organizations, and social forces to develop various subjects (Yu et al., 2008).

For China, after the outbreak of COVID-19, China quickly launched a pack${ }^{1}$ After an epidemic has been declared by the WHO as a PHEIC, it is equivalent to sending a clear signal to countries around the world: Without a large-scale response, the epidemic will not be properly controlled. Governments should also assess the need for important social interventions, such as closing schools or lifting large gatherings, and even imposing travel bans on specific areas. 
age of plans. In order to ensure "anti-epidemic", the society actively donated money and materials, and the Chinese government quickly arranged special funds (Figure 1). At the same time, the Chinese government has also promulgated various policies, including fiscal policy, tax policy, monetary policy, industrial policy, employment policy.

In terms of fiscal policy, a combination of tax reduction, fee reduction, and subsidies were issued, and "Anti-Epidemic Thematic Bond" was issued. The government has given preferential treatment to industries affected by the epidemic, such as transportation, catering, tourism, accommodation, express delivery, civil aviation and other industries. According to preliminary estimates, the general public budget deficit rate in 2020 may increase from $2.8 \%$ of GDP to about $3 \%$.

In terms of monetary policy, it has also maintained enough loose. Through measures such as Balance Sheet Expansion, RRR-cutting, and policy interest rate cutting, $\mathrm{POBC}$ ensures sufficient liquidity and no increase in financing costs for the real economy at the same time as fiscal strength. At present, the central bank's special anti-epidemic refinancing quota has reached 800 billion Yuan. At the same time, under the condition of impaired external demand and flat foreign exchange reserves, $\mathrm{PBOC}$ launched a targeted RRR - cutting to support the growth of total social financing.

A more direct stimulus plan comes from "new infrastructure." In order to combat the negative impact of COVID-19, as of March 1, 13 provinces including Beijing, have released investment plans for key projects in 2020 with a scale of up to 33.8 trillion Yuan. Among them, "new infrastructure" is highly expected. "New infrastructure" is different from traditional infrastructure such as railroad, highway, airport, and mainly includes " $5 \mathrm{G}$ infrastructure, UHV, intercity high-speed railway and urban rail transit, new energy vehicle charging piles, big data centers, artificial intelligence, industrial Internet" 7 aspects (Chen, 2020).

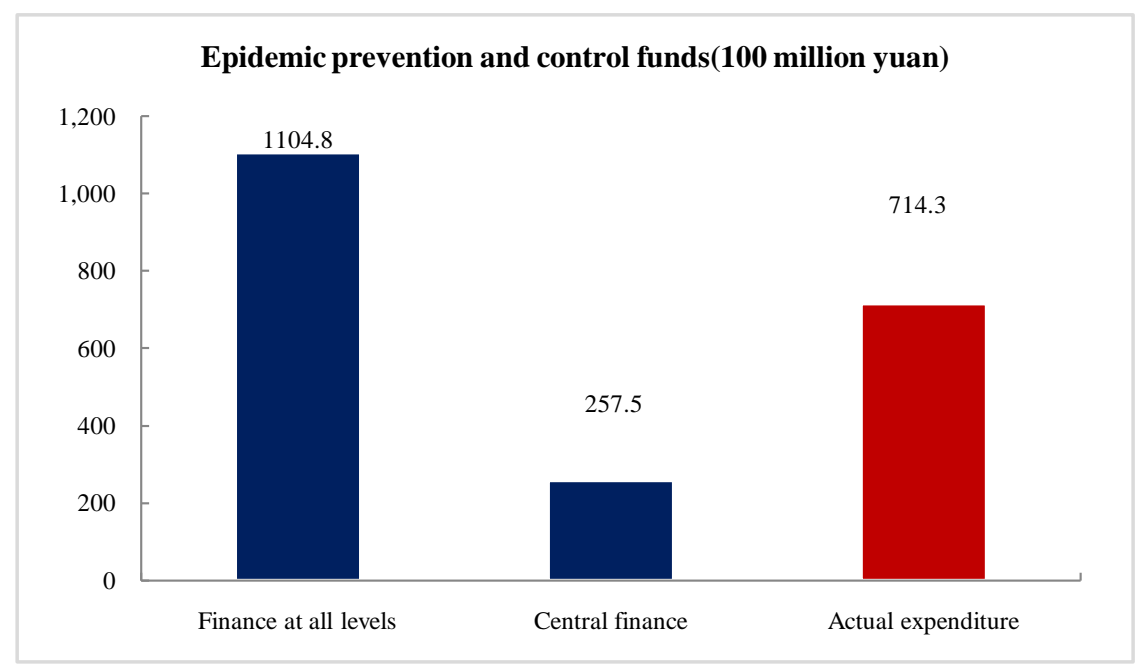

Figure 1. Funds for epidemic prevention and control arranged by finances at all levels. Source: State Councip s Press Conference on Joint Prevention and Control Mechanism, March 2, 2020. 
In terms of employment policy, on the one hand, the government reduced the burden on enterprises through tax and fee reduction policies. On the other hand, the government is actively expanding employment channels. These channels include expanding recruitment plans for state-owned enterprises, expanding employment at the grassroots level (such as supporting agriculture, education, medical care, and poverty alleviation, etc.), expanding the size of employment trainees, organizing "Cloud" Job Fairs for graduates, and appropriately delaying the acceptance.

It can be seen that under the severe impact of the epidemic, China has continuously adopted public health policies, fiscal policies, monetary policies, industrial policies, and employment policies, etc., which are highly targeted and very powerful. Therefore, this paper tends to believe that the first quarter should be the bottom of the short-term economy, and then it will show a "bottom rebound and overall soundness". Throughout the year, the likelihood of completing the employment and growth targets set by the Central Economic Work Conference remains high. And in the world, the greater recovery of China's economy is also expected to lead the recovery of the global economy (Yang, 2020).

\section{Mid-and Long-Term Impact of the Epidemic on China's Economy}

\subsection{The Historical Impact of the Epidemic on the Economy Has Been Limited, But Historical Experience Cannot Be Simply Copied}

There is not much discussion about the mid-to-long term impact of the epidemic on China's economy. At present, most discussions tend to think that the epidemic is a short-term supply-side shock with limited long-term economic and financial impact. Most of these studies have adopted historical contrast methods. For example, Hua et al. (2020) sorted out the epidemics brought about by the top ten major infectious diseases in the world in the past 20 years, including Pneumonic Plague in India in 1994, SARS in China in 2003, Bird Flu in 2006 in China, H1N1 in 2009 in American, MERS in 2012 and 2015, etc. pointed out that the economic impact of these epidemics are characterized by a slightly stronger short-term intensity, but not persistent.

Indeed, a simple comparison of history will reveal that there is no simple consistency between the epidemic and economic growth. Take SARS and H7N9, which have spread significantly in China as an example. In 2003, when SARS occurred, China's GDP growth rate was 0.9 percentage points faster than that in 2002. In 2017, when H7N9 raged in China, China's economic growth was higher than 2016 by 0.1 percentage point.

However, things are not so simple. On the one hand, COVID-19 is more infectious and has a higher R0 value. On the other hand, the current internal and external environment of China's economy is different from the past. First, consumption and service industries account for a high proportion of China's current economic structure. Second, the epidemic is basically controllable in China, 
and the resumption of production and work are proceeding in an orderly manner. However, because the global epidemic is still relatively uncertain, the spillover effect on China's economy is obvious. Third, China is currently in a very critical position in the global value chain. The spread of the epidemic will adversely impact China's important position in the global supply chain. On January 30, US Secretary of Commerce Rose said in an interview with Fox News that COVID-19 would "give businesses yet another thing to consider when reviewing their supply chain". In the long run, the epidemic will accelerate the transfer of multinational companies from China to other alternative regions. It is likely to change from the original "China +1 " industrial transfer model to the "China + n" $\operatorname{model}^{2}$ (Zhu et al., 2020).

Therefore, this paper uses the framework of classic economic growth theory to analyze the mid-to-long term impact of the epidemic in a macro sense. In the medium and long term, the epidemic will affect the changes in the concepts and behavior patterns of residents, governments, and enterprises, which will lead to changes in some important macroeconomic variables, and will have a profound impact on China's economy and the world economic structure.

According to the production function $Y=F(K, A L)=K^{\alpha}(A L)^{1-\alpha}$ (where $A, K$, and $L$ are the technical level, capital stock, and labor force, respectively), the actual economic growth rate of a country will fluctuate in the short term due to the influence of demand factors. But in the medium and long term, it depends mainly on the supply of factors and is reflected in the potential output level. Therefore, the potential growth rate is determined by the supply factors of labor, capital, and total factor productivity (TFP). Among them, FTP is a "residual value", that is, the part of economic growth that cannot be explained by the input of factors such as capital and labor. It is usually used to measure the additional economic growth brought about by technological or institutional innovation. The transmission path of the epidemic shock to TFP is relatively complicated, and the influence of action is uncertain. The labor factors are highly related to population structure and education level, and the impact of the epidemic on them can be ignored. Comparatively, the impact of the epidemic on capital factors may be realized through the rise in the savings rate, so the following will be carried out in detail.

\subsection{China's Savings Rate May Rebound with Preventive Motivation}

Generally speaking, the occurrence of catastrophic risk events such as the epi-

${ }^{2}$ As China's labor costs and other business costs continue to increase, in order to avoid and diversify the risks of investing solely in China, multinational companies have relocated some of their capacity that had been directly invested in China to third-party countries around China. These countries often have abundant labor resources and their production costs are much lower than China. Preferred third-party countries are ASEAN members such as Vietnam, Indonesia, Thailand, etc. The "China + 1 ” strategy was first adopted by Japanese multinational companies in China, and later emulated by European and American multinational companies in China. After the outbreak of the Sino-US trade war, the "China +1 " strategy of transnational corporations has evolved into the "China +2 " and "China $+\mathrm{n}$ " strategies. 
demic situation and the financial crisis may affect people's marginal consumption tendency, but there may be two paths in opposite directions. In the micro-area of consumption and savings theory, the disputes over "preventive saving" motivation and "just in time" also exist for a long time (Yao \& Xu, 2018).

One view is that residents are more inclined to act conservatively when facing risks. In this case, natural disasters may inspire the residents of the disaster-stricken areas to "preventive savings" motivations, prompting them to reduce consumption and increase savings to smooth potential negative results. Another view is that the disaster may make residents in the disaster area aware that life is limited, thereby increasing consumption and using the available time and money as much as possible for current leisure activities. There is a lot of evidence in the academic community in support of preventive savings, and these can be confirmed from macro experience, which are following:

China's savings rate is relatively high worldwide, and has been consistently higher than $40 \%$ since 2003 . The factors may come from many aspects, such as higher income growth, demographic dividends, and conservative consumption concepts. Of course, the high propensity for preventive savings is also one of the important reasons. Choi et al. (2017) even consider that $80 \%$ of Chinese household savings are preventive savings. And a person's experience may affect his subsequent propensity to consume. The groups that experienced famine in the 1960s are more frugal. Even if the standard of living improves later, this frugal habit will continue, and will be passed on to next generations through by word and personal example, and the impact of the Great Famine on China's savings rate is profound (Cheng \& Zhang, 2011). In 2003 and subsequent years, China's savings rate did increase. The factors affecting the savings rate were more complex, and the impact of the SARS epidemic may be just one of them (Figure 2).

According to research by international scholars similar phenomena have occurred globally. The "Gig Flu" that broke out from 1918 to 1920 was a more serious public health event, with about 40 million deaths worldwide, including more than 600,000 in the United States. Brainerd and Siegler (2003) argue that the "Big Flu" increased the preventive savings of US residents and boosted US economic growth in the 1920s. After the subprime mortgage crisis and the impact of H1N1 influenza, the lifestyle of American residents has changed to a certain extent, and the savings rate has picked up (Figure 3).

\subsection{Rising Savings Propensity Could Lead to Rising Potential Output in China}

So how will the increase of the savings rate affect China's potential output? Consider the classic Solow Model (Solow, 1956): A frequently used production function is the Cobb-Douglas production function:

$$
Y=F(K, A L)=K^{\alpha}(A L)^{1-\alpha} 0<\alpha<1
$$

Among them, the form of the consumption function C: 


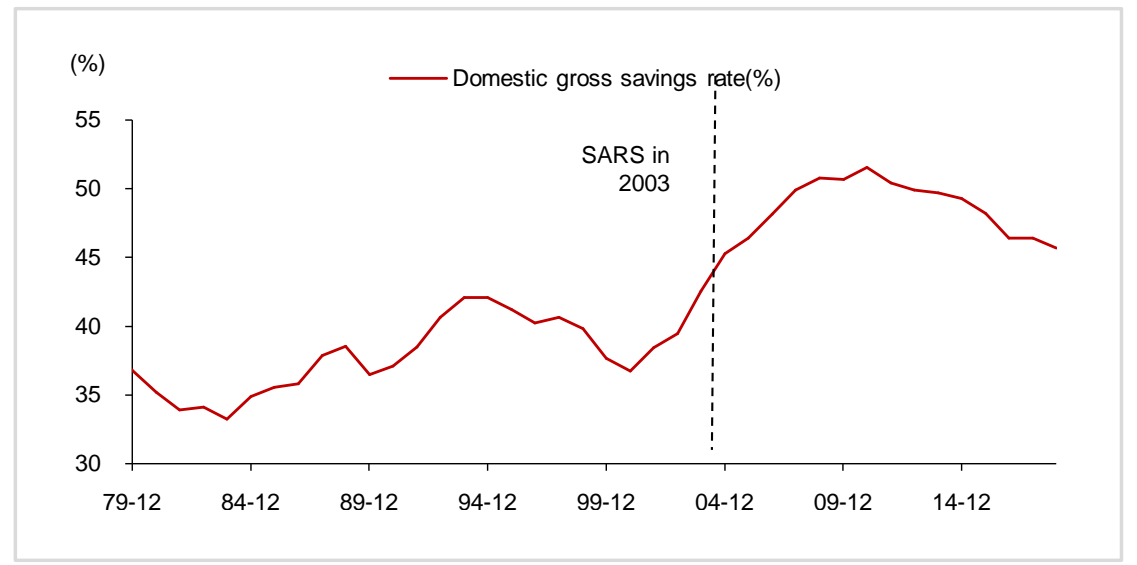

Figure 2. China's savings rate is relatively high (1979-2019). Source: National Bureau of Statistics.

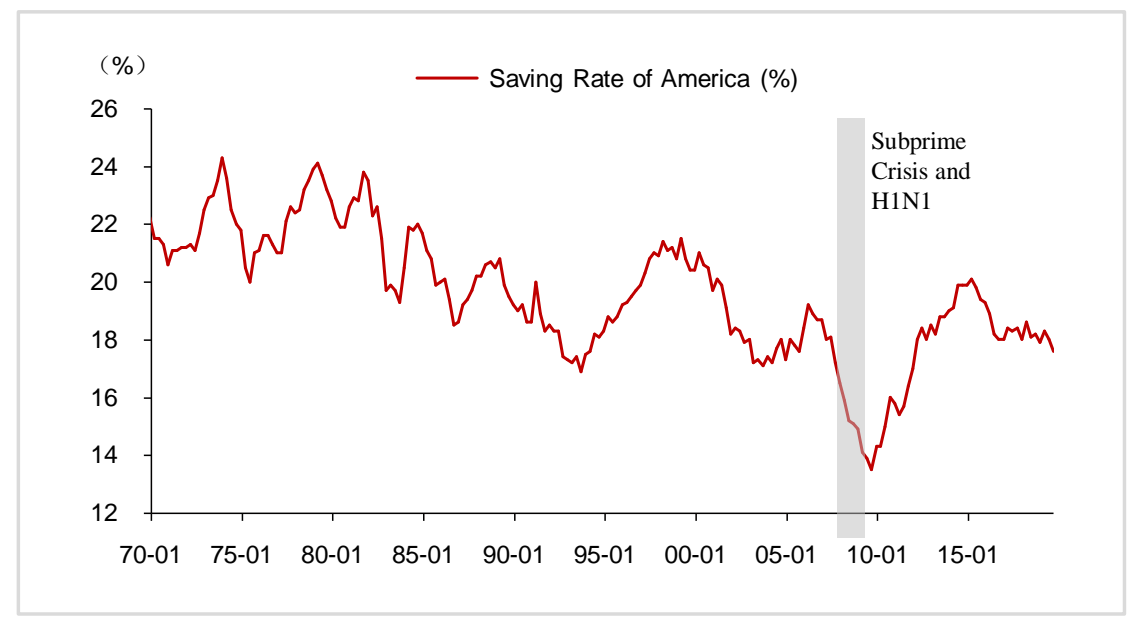

Figure 3. US savings rate rebounds sharply after Subprime Crisis and H1N1 (1970-2019). Source: CEIC.

$C=(1-s) Y 0<s<1$. where $s$ is the saving rate, which is generally assumed to be constant, that is exogenously. So $I=s Y$, the conversion of savings into investment at no cost.

Derived from the Solow Model, suppose $k=K / A L$,

$$
\begin{aligned}
& \therefore \dot{k}=\frac{\dot{K}}{A L}-\frac{K}{(A L)^{2}}[A \dot{L}+L \dot{A}]=\frac{\dot{K}}{A L}-\frac{K}{A L} \frac{\dot{L}}{L}-\frac{K}{A L} \frac{\dot{A}}{A} \\
& =s f(k)-(n+g+\delta) k
\end{aligned}
$$

Therefore, $s f(k)=(n+g+\delta) k$ determines the expression of steady state $k$, and $n$ represents the rate of population growth, $g$ represents the rate of technological progress, and $\delta$ is the rate of depreciation. In the case of exogenous changes in the saving rate, observe the change and magnitude of the potential output. Assuming a stable $s_{\text {old }} \uparrow s_{\text {new }}$, there will be a sudden increase in investment (Figure 4). Under the impact of $s$, the system shifts from the old equilibrium $k_{\text {old }}^{*}$ to the new equilibrium $k_{\text {new }}^{*}$. 


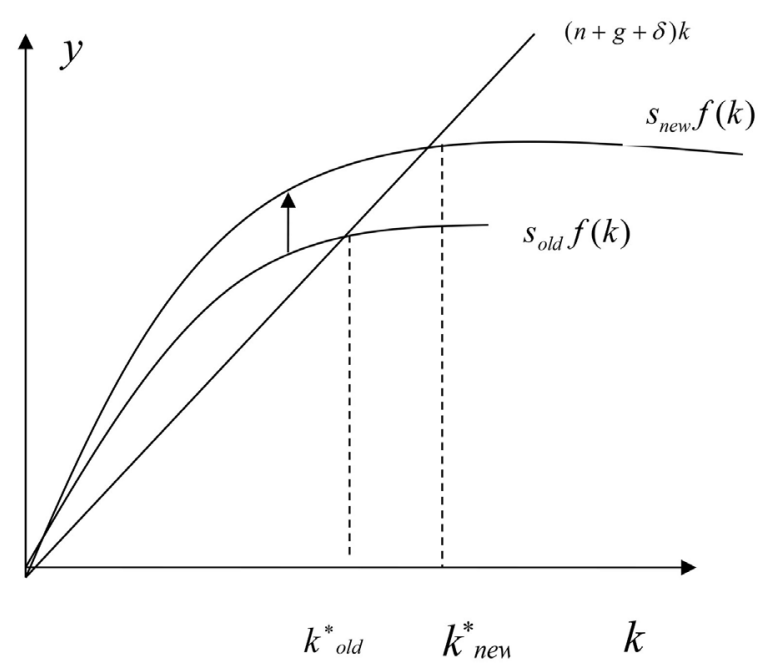

Figure 4. New steady state with rising savings rate.

The specific process is: Sudden increase $s$, according to $\dot{k}=s f(k)-(n+g+\delta) k$, would lead a sudden increase of $\dot{k}$. So $\dot{y}$ umpscorrespondingly. Consider per capita output $\left(\frac{Y}{L}\right)=A f(k)=A y$, and

$$
\begin{aligned}
& \frac{\left(\frac{\dot{Y}}{L}\right)}{\left(\frac{Y}{L}\right)}=\frac{A \dot{y}+\dot{A} y}{A y}=\frac{\dot{y}}{y}+\frac{\dot{A}}{A}=\frac{f^{\prime}(k)}{f(k)} k^{\prime}+g \text {, and } \\
& {\left[\frac{f^{\prime}(k)}{f(k)}\right]^{\prime}=\frac{f^{\prime \prime}(k) f(k)-\left[f^{\prime}(k)\right]^{2}}{[f(k)]^{2}}<0, \text { So after the jump, the growth rate of }}
\end{aligned}
$$
per capita output will decrease to $\mathrm{g}$, as $\dot{k}$ gradually decreases to 0 .

So using the Solow Model, we can conclude that as the motivation for saving rises, the potential growth rate of China's economy will experience an acceleration and then a return to normal.

\subsection{But the Rising Propensity of Saving May Also Lead to Increased Overcapacity and Increased Global Economic Imbalances}

Dynamically, however, the rising savings rate will also bring negative effects. Considering an open economic environment, due to the increase in investment, the diminishing marginal return of capital will lead to a decline in the rate of return on capital, which will easily lead to an imbalance in the internal economic structure and an increase in overcapacity. At this time, exchange rate depreciation and net exports of goods and services are needed to achieve balance. In fact, after 2003, China's exports grew rapidly and a large-scale trade surplus was formed, partly due to the globalization dividend of China's accession into WTO, and partly due to the increase in China's savings and investment rates (Figure $5)$. 


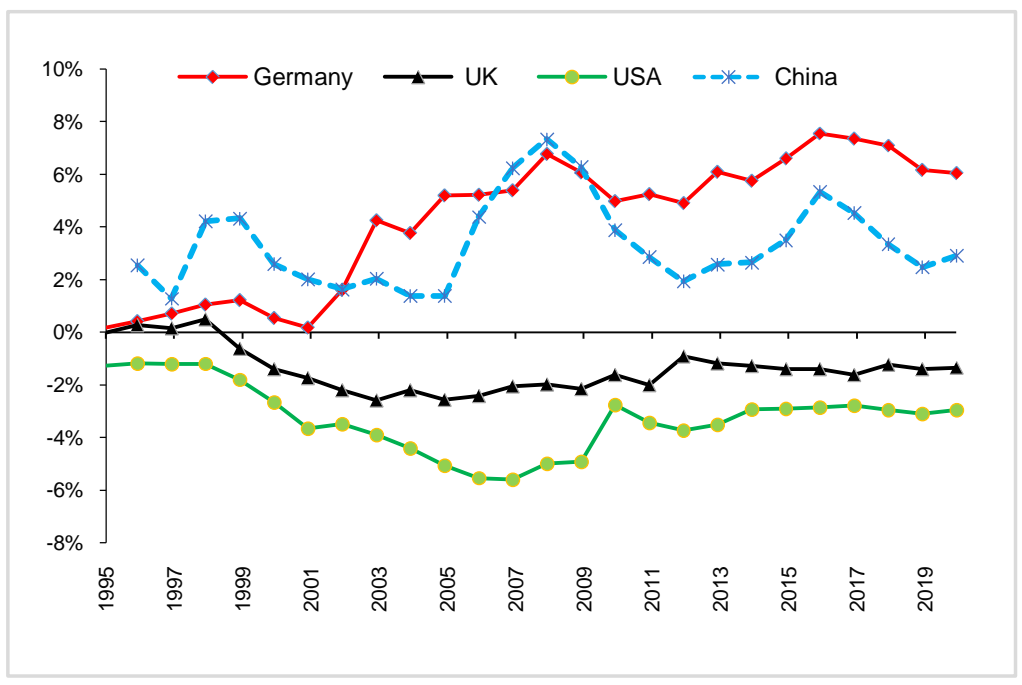

Figure 5. Proportion of trade balance of major global economies to GDP (1991-2019). Source: CEIC.

However, this kind of structural imbalance can easily cause trade frictions between countries. Among them, the imbalance and friction between China and the United States are the most obvious. As early as 2005, the RMB was forced to appreciate the dollar. By 2018, trade frictions and conflicts between China and the United States have escalated, and there is still no sign of easing. Therefore, with regard to China's rising propensity for preventive savings, it is necessary to adopt institutional changes in the medium and long term, taking into account the internal and external balance of the Chinese economy (Figure 5).

It can be expected that as China's savings rate rises again, China's export pressure will increase, which requires coordination of economic and trade relations with the United States to prevent the continuous escalation of friction. At the same time, emerging market countries and countries along the "Belt and Road", as hot spots in China's economic and trade fields and investment fields, may take over China's excess savings and investment after the epidemic. This means that in the medium term, a new global economic and investment structure will also be formed.

\section{Conclusions and Policy Recommendations}

In summary, as a major public health event, COVID-19 has abroad population coverage and a severe impact on economic activity in China and the world. Therefore, its short-term, medium- and long-term impact on China's economy cannot be ignored.

In the short term, under the impact of the epidemic and effective policy responses, China's economy may rebound after a sudden stall. However, in the medium and long term, the epidemic may stimulate the savings motivation of Chinese residents, and the increase in the saving rate may cause an increase in China's potential growth rate, while may also increase the export tendency of China's economy, which may cause a new pressure on external demand rebalancing. 
Therefore, the Chinese government needs to actively encourage consumption while strengthening international collaboration. Therefore, the policy recommendations in this paper include:

1) Policies should be rapid and powerful, but they should not be applied too vigorously. Considering the epidemic is controllable and the short-term economic impact can be expected, the total amount of stimulus policies should not be excessive and low efficiency. Looking back to the " 4 trillion" stimulation plan in 2008, it brought about problems such as overheated economy, debt inflation, and excess capacity, which are still worthy of reference.

2) Actively carry out reforms to increase marginal consumption propensity. These measures should include improving the social security system, further deepening the reform of the housing, medical care and education systems, and alleviating the preventive anxiety of residents. And reducing the gap in income distribution and advancing the "tackling of poverty" are also the means of the subject.

3) Promote international communication, coordination and cooperation. COVID-19 poses a challenge to global public health and economic growth. Whether the world, especially China and the United States, can join hands is a topic worthy of attention. After the epidemic, how to strengthen mutual trust and cooperation, and jointly face the reshaping of the global economic structure of the epidemic, would also pose new challenges for China and the United States. In addition, emerging markets and the "Belt and Road" countries, as potential markets, will also be the main destinations for China's savings and investment after the "epidemic", so plans need to be made in advance.

4) Promote innovation and upgrading of industries. The epidemic brought significant negative effects, but also brought about changes in production and lifestyle. Among them, the degree of automation of enterprises has increased, the development of big data, cloud computing, and robots have accelerated, and the import substitution of the semiconductor industry chain will also accelerate. From the perspective of life, residents' awareness of healthy living has increased, and requirements for quality of life improve. The government should follow the trend and guide China's industries towards high-quality development.

Of course, this paper is only from the perspective of saving and investment to explore the mid-and long-term impact of the epidemic. It can be imagined that with the development of the epidemic situation and the systemic linkage, studies on the economic impact of the epidemic may be more accurate and informative.

\section{Conflicts of Interest}

The authors declare no conflicts of interest regarding the publication of this paper.

\section{References}

An, G. J., \& Jia, W. W. (2020). Analysis of the Impact of COVID-19 on the Economy and Countermeasures. Financial Theory and Practice, No. 3, 45-51. 
Brainerd, E., \& Siegler, M. V. (2003). The Economic Effects of the 1918 Influenza Epidemic. CEPR Discussion Paper No. 3791.

Chen, Z. K. (2020). China Speeds Up “New Infrastructure” Progress. People's Daily Overseas Edition. http://it.people.com.cn/n1/2020/0311/c1009-31626580.html

Cheng, L. G., \& Zhang, Y. (2011). Did the Famine Experience in the Early Years Affect People's Saving Behavior?-A New Explanation of the High Saving Rate of Chinese Residents. Economic Research, No. 8, 119-132.

Choi, H., Lugauer, S., \& Mark, N. C. (2017). Precautionary Saving of Chinese and US Households. Journal of Money, Credit and Banking, 49, 635-661. https://doi.org/10.1111/jmcb.12393

Hu, M. S. (2020). Distressed Migrant Workers in the Epidemic. Southern Metropolis Daily. https://www.sohu.com/a/379782380_161795

Hua, C. C., Zhang, J., Han, X., \& Tian, Y. D. (2020). Looking at the Impact of the 2019-nCoV and Global PHEIC Events from the Top Ten Infectious Disease Events Worldwide. Sina Finance. https://finance.sina.cn/2020-02-01/detail-iimxyqvy9504290.d.html?ivk_sa=1023197a

Joo, H., Maskery, B. A., Berro, A. D., Rotz, L. D., Lee, Y. K., \& Brown, C. M. (2019). Economic Impact of the 2015 MERS Outbreak on the Republic of Korea's Tourism-Related Industries. Health Security, 17, 100-108. https://doi.org/10.1089/hs.2018.0115

Lu, Y. N., Li, X. P., Zhao, Z. H., \& Yu, J. X. (2020). Don't Be Afraid of Short-Term Shocks (The Fundamentals of the Economy Have Improved for a Long Time)-China Economic Watch under the Influence of the Epidemic. People's Daily. http://paper.people.com.cn/rmrb/html/2020-03/15/nw.D110000renmrb_20200315_3-0 $\underline{1 . h t m}$

Shen, G. B. (2020). Impact of COVID-19 Epidemic on China's Foreign Trade and Employment, and Rescue Measures. Journal of Shanghai University of International Business and Economics, No. 3, 16-25.

Solow, R. M. (1956). A Contribution to the Theory of Economic Growth. Quarterly Journal of Economics, 70, 65-94. https://doi.org/10.2307/1884513

Song, Q. H. (2020). COVID-19 Epidemic Spawned Two New Economic Formats. Business China, No. 3, 48-49.

Yang, P. P. (2020). Global Spread of Epidemic Impacts World Economy. Hope, No. 10. http://lw.xinhuanet.com/2020-03/11/c_138864779.htm

Yao, D. Z., \& Xu, Y. Z. (2018). Natural Disasters and Residents' Saving Behaviors: A Micro-Econometric Test Based on the Wenchuan Earthquake. Economic Developments, No. 5, 56-70.

Yu, N., \& Research Group of Financial Research Office in Chengdu Branch of the People's Bank of China (2008). Comparison and Reference of Experiences in Restoration and Reconstruction in Some Countries and Regions after the Catastrophe: Based on the Perspective of Fund Raising Methods and Systems. Southwest Finance, No. 9, 14-16.

Zhou, H. C. (2020). Regarding the Crisis as an Opportunity under COVID-19. Business China, No. 3, 50-51.

Zhu, K. F., Gao, X., Yang, C. H., \& Wang, S. Y. (2020). The COVID-19 Shock on Global Production Chains and Risk of Accelerated China's Industrial Chains Outflow. Bulletin of the Chinese Academy of Sciences, No. 3,283-288. 